\title{
Prevalence of glaucoma in an African population
}

CT Ntim-Amponsah', WMK Amoaku²,

S Ofosu-Amaah ${ }^{3}$, RK Ewusi ${ }^{4}$, R Idirisuriya-Khair ${ }^{3}$,

E Nyatepe-Coo ${ }^{3}$ and M Adu-Darko

\begin{abstract}
Purpose To determine the prevalence of primary open-angle glaucoma (POAG) in a Ghanaian population aged 30 years and above and to describe any ethnic variations in glaucoma prevalence in this population. Method A cross-sectional prevalence survey for POAG was carried out on residents of $\mathbf{3 0}$ years and above in the Akwapim-South district of Ghana. The principal investigator examined all glaucoma suspects and those diagnosed as glaucoma in the initial screening to determine all definite cases of POAG. All cases had intraocular pressure measurements. Glaucoma cases and suspects and some normal subjects had fundus biomicroscopy with 78 D Volk lens, and Humphrey FDT N-30 visual fields plotted.

Results A total of 1843 people aged 30 years were screened from the population. The standardized age-specific prevalence was $7.7 \%$ ( 30 years and above) and $8.5 \%$ (40 years and above). The best-fit trend line for prevalence/ age relationship was exponential. No gender or ethnic difference in prevalence was found. Conclusions The prevalence of POAG in this population is high and comparable to those in black populations in Barbados and St. Lucia Eye (2004) 18, 491-497. doi:10.1038/sj.eye.6700674
\end{abstract}

Keywords: glaucoma; glaucoma prevalence; african population

\section{Introduction}

There are different clinical impressions about the prevalence and severity of glaucoma in West Africa. Clinicians in southern coastal areas report the occurrence of severe primary openangle glaucoma (POAG) and chronic angle closure glaucoma (CACG), while in the savanna POAG is considered less prevalent and therefore less of a problem. ${ }^{1}$ These impressions, however, are based on hospital data and blindness prevalence studies. Prevalence estimates based on blindness surveys may underestimate glaucoma prevalence because POAG is asymptomatic, and visual acuity and fields are only affected in the late stages of the disease. In Ghana, these data suggest that glaucoma is the most common cause of irreversible blindness. ${ }^{2,3}$ However, there is a significant lack of epidemiological data on glaucoma in Ghana in particular ${ }^{4}$ and Africa in general. ${ }^{1,5}$ The Baltimore Eye Survey report suggests that African Americans have approximately four times greater risk of chronic simple glaucoma than American whites. Similarly, the Barbados study found a high prevalence of glaucoma in this African Caribbean population. ${ }^{5}$

Ghana is a country in West Africa with a population of about 18.4 million. ${ }^{6}$ Life expectancy at birth is 57 years for males and 61 years for females and is on the increase. ${ }^{6}$ As age is an important risk factor for POAG and as life expectancy increases in Ghana, and the rest of Africa, it is expected that glaucoma will pose an increasing burden on eye care services.

The objectives of this study were to determine the prevalence of POAG in the Akwapim South district of Ghana and evaluate differences in prevalence among different ethnic groups if present.

\section{Materials and methods}

There are 110 districts, which form the basic health units in Ghana. The prevalence of glaucoma is high in hospital attendants in the Akwapim-South district in the Eastern Region. ${ }^{7}$ The district's multiethnicity (major ethnic groups are Akwapims, Ewes, Akims, and GaAdangbe) ${ }^{8}$ confirmed by interviews with residents who were opinion leaders, and the relative accessibility of towns and villages, which are relatively densely populated, made it a suitable area for this study.

The study population consisted of all Ghanaians who were 30 years or older living in the Akwapim-South district. The project aimed at screening about $5 \%$ of the eligible population, \\ 'University of Ghana \\ Medical School \\ Accra, Ghana \\ ${ }^{2}$ Division of Ophthalmology \\ and Visual Sciences \\ University of Nottingham \\ Queen's Medical Centre \\ Nottingham, UK \\ ${ }^{3}$ School of Public Health \\ University of Ghana \\ Accra, Ghana \\ ${ }^{4}$ Korle-Bu Teaching Hospital \\ Korle-Bu \\ Accra, Ghana \\ ${ }^{5}$ School of Medical Sciences \\ University of Science and \\ Technology \\ Kumasi, Ghana \\ Correspondence: \\ WMK Amoaku \\ Division of ophthalmology \\ and Visual Sciences \\ University of Nottingham \\ Queen's Medical Centre \\ Nottingham NG7 2UH, UK \\ Tel: +4401159249924x \\ 43757 \\ Fax: + 4401159709749 \\ E-mail:wma@ \\ nottingham.ac.uk
}

Received: 31 July 2001 Accepted in revised form: 10 June 2003 
based on resources available, in a cross-sectional survey. With the help of the community health nurses of the only eye clinic in the district and a district map, towns and villages in the district that had a high proportion of ethnic diversity were marked. The principal investigator spent a day going round the district to identify the marked places in order to confirm ethnic diversity from the inhabitants, their willingness to participate and also assess the density of the population and accessibility by road.

In all, 18 towns and villages were identified as eligible based on multiethnicity, accessibility, and population density. One of the assistants who did not know the district selected 14 out of these 18 towns by simple random sampling. The original study design was to use systematic sampling, but this had to be changed after the pretesting stage owing to several circumstances that made systematic sampling impracticable. Eligible subjects were Ghanaian individuals who were 30 years or older and resident in the Akwapim-South district. The survey was discussed with opinion leaders in the localities, who were instrumental in explaining the survey to the people and encouraged eligible subjects to participate throughout the duration of the study, which was conducted from August 2000 to March 2001. All participants were encouraged to bring other members of their families and dwelling units to participate in the study.

All residents who consented after the study was explained to them were recruited. Research assistants measured the visual acuity with a Snellen's chart. Clinical examination was carried out by a trained ophthalmologist (the principal investigator) assisted by an ophthalmology resident on each visit (three residents rotated). Intraocular pressure (IOP) was measured with the tonopen or Perkin's tonometer. It was intended to use tonopen for initial pressure measurement only and then Perkin's applanation tonometer to repeat measurement in all subjects considered as suspects and glaucoma cases. The tonopen broke down after the first $10 \%$ had been examined and so the Perkin's tonometer was used for the rest of the project (both initial and re-examination). Optic disc status was assessed with a direct ophthalmoscope initially. Glaucomatous looking discs and glaucoma suspects were reassessed by biomicroscopy with a $78 \mathrm{D}$ Volk lens, except when cupping was obviously so advanced with the widest vertical cup-disc ratio greater than 0.8 . Gonioscopy was performed by the principal investigator to assess the anterior chamber angle at the same time. Visual fields were plotted using Humphrey frequency doubling technology (FDT) visual field analyser (based in a private clinic in Accra that is very close to the district) using full threshold N-30. (This is comparable to the traditional
Humphrey 24-2 visual fields.) Visual fields were plotted for all participants declared by the principal investigator as suspects of glaucoma, and one in 20 normals.

To maximize the turn out, an ambulance transported most of the subjects from the district to Accra on Saturdays for the visual field recordings, except those who preferred to go on their own. The principal investigator re-examined all the glaucoma suspects to determine their classification as definite glaucoma or otherwise, established cases of glaucoma, as well as 10\% of normals in order to determine the accuracy of screening. Subjects who were found to have highpressure glaucoma were given a free bottle of $0.5 \%$ timolol eye drops, except when contraindicated, and also referred to see the principal investigator or any other ophthalmologist of their choice. The ethics of the study protocol was approved by appropriate committee of the University of Ghana.

\section{Case definitions (European Glaucoma Study Guidelines)}

The diagnosis of glaucoma was based on glaucomatous optic nerve damage, including abnormal visual fields and/or optic disc cupping with or without elevated IOP (by Perkin's applanation tonometer).

Definition of glaucoma suspects: IOP $>21 \mathrm{mmHg}$, IOP of difference $>4 \mathrm{mmHg}$ between the two eyes, or a glaucomatous visual field defect. The optic disc was referred to as suspicious when the cup/disc ratio was greater than 0.5 , or there was an unequal cup/disc ratio with a difference of more than 0.1 between the two eyes.

Glaucoma cases were subjects on treatment for POAG or newly diagnosed during the survey. The major diagnostic criterion was evidence of structural optic nerve damage. Additional criteria were visual field defect and/or raised IOP.

The indicators of POAG were therefore:

(a) Optic disc status: When there was evidence of glaucomatous optic nerve damage, that is, cupping of $>0.5$ with or without notching supported by visual field changes, it was referred to as glaucomatous. When there was no such evidence of glaucoma, it was referred to as nonglaucomatous.

(b) IOP: IOPs were considered normal if it was $<22 \mathrm{mmHg}$. Values $>21 \mathrm{mmHg}$ or a difference of $4 \mathrm{mmHg}$ or more between the two eyes were considered abnormal.

(c) Visual fields: Subjects with visual field defects suggestive of glaucoma were confirmed as glaucoma if there was either glaucomatous optic disc changes or high IOP. The presence of one or more absolute defects in the central $30^{\circ}$ was acceptable as glaucomatous. Field changes that were considered typically glaucomatous included defects $>5^{\circ}$ diameter centrally and of shape 
and distribution typical of optic nerve damage, paracentral or arcuate scotomas and nasal steps. In advanced cases, central or temporal islands were found. The presence of abnormal repeatable field defect with or without elevated IOP in one or both eyes or visual loss so advanced that visual field testing is impossible was classified as glaucomatous. Fixation loss, false-positive and false-negative responses were also monitored to ensure reliability. Those with no visual field defect that could be attributed to glaucoma were labelled as nonglaucomatous field changes.

\section{Results}

A total of 1843 people were screened forming $4.4 \%$ of the total population of the Akwapim-South district aged 30 years and above (no statistics on population in individual towns are available). In total, 58 were not eligible for analysis because they had ocular media opacities that made the optic disc inaccessible for assessment, thus leaving 1785 as eligible. These included 893 females and 892 males. The mean age of the population was 50 years, median 48 years and SD 14.43. The age/sex distribution of the study population is summarized in Table 1 . The age/sex distribution of the study population is similar to that of the general (national) population.

At the final evaluation, a total of 158 cases of glaucoma were diagnosed. Out of the 158 cases of glaucoma, 149 $(94.3 \%)$ were of the primary open-angle type, while nine $(5.7 \%)$ were of the chronic angle closure type. Included in the POAG were 33 cases $(20.9 \%)$ of normal tension glaucoma. In all, 93\% were newly diagnosed, while the rest were known glaucoma patients. A total of 15 (9.5\%), out of which 12 were new cases, were unable to count fingers at $3 \mathrm{~m}$ and were considered blind. There were 11

Table 1 Age/sex distribution of sample

\begin{tabular}{lrrrrc}
\hline Age group (years) & $F$ & $M$ & Total & $\%$ & Cumulative \\
\hline $30-34$ & 114 & 138 & 252 & 14.1 & 14.1 \\
$35-39$ & 118 & 106 & 224 & 12.5 & 26.6 \\
$40-44$ & 128 & 129 & 257 & 14.4 & 41 \\
$45-49$ & 107 & 93 & 200 & 11.2 & 52.2 \\
$50-54$ & 111 & 134 & 245 & 14.0 & 66.2 \\
$55-59$ & 53 & 71 & 124 & 6.9 & 73.1 \\
$60-64$ & 92 & 73 & 165 & 9.2 & 82.3 \\
$65-69$ & 41 & 59 & 100 & 5.6 & 87.9 \\
$70-74$ & 54 & 36 & 90 & 5.0 & 92.9 \\
$75-79$ & 31 & 17 & 48 & 2.7 & 95.6 \\
$80-84$ & 32 & 17 & 49 & 2.7 & 98.3 \\
$85-89$ & 6 & 10 & 16 & 0.9 & 99.2 \\
$90-94$ & 2 & 7 & 9 & 0.5 & 99.7 \\
95-100 & 4 & 2 & 6 & 0.3 & 100 \\
Grand total & 893 & 892 & 1785 & 100 & \\
\hline
\end{tabular}

$(6.9 \%)$ with positive family history of glaucoma in firstdegree relations. Five of these relatives were discovered at the time of the survey. There were 23 glaucoma suspects and 10 with ocular hypertension (at the final evaluation) who were not included in the analysis for prevalence. None of the normal nonglaucomatous participants had visual field defects that are characteristic of glaucoma.

Prevalence of glaucoma by age is summarized in Table 2 and plotted in Figure 1.

The overall prevalence of glaucoma in the population was $8.4 \%$ (8.2\% in females, $8.6 \%$ in males) with a $95 \%$ confidence interval of $7.74-9.06 \%$. There was no statistical difference in gender prevalence of POAG at any age $\left(\chi^{2}\right.$ test, $P=0.66$ for $30-100$ years; $P=0.64$ for 30-64 years). The standardized age-specific prevalence was $7.7 \%$ for ages 30 years and above and $8.5 \%$ for ages 40 years and above. The prevalence of POAG in the 30- to 64-year age group was $6.61 \%$ (95\% CI 5.46-7.76\%). This age group contributed $82.12 \%$ (1467) of the total eligible

Table 2 Prevalence of POAG by age groups

\begin{tabular}{lccc}
\hline $\begin{array}{l}\text { Age group } \\
\text { (years) }\end{array}$ & $\begin{array}{c}\text { No. of cases } \\
\text { POAG }\end{array}$ & $\begin{array}{c}\text { Total } \\
\text { population }\end{array}$ & Prevalence (\%) \\
\hline $30-34$ & 15 & 252 & 6.0 \\
$35-39$ & 13 & 224 & 6.7 \\
$40-44$ & 16 & 257 & 6.2 \\
$45-49$ & 13 & 200 & 6.5 \\
$50-54$ & 18 & 245 & 7.3 \\
$55-59$ & 8 & 124 & 6.5 \\
$60-64$ & 13 & 165 & 7.9 \\
$65-69$ & 10 & 100 & 10.0 \\
$70-74$ & 12 & 90 & 13.3 \\
$75-79$ & 13 & 48 & 27.1 \\
$80-84$ & 13 & 49 & 26.5 \\
$85-89$ & 0 & 16 & 0 \\
$90-94$ & 3 & 9 & 33.3 \\
$95-100$ & 1 & 6 & 16.7 \\
Grand total & 149 & 1785 & 8.4 \\
\hline
\end{tabular}

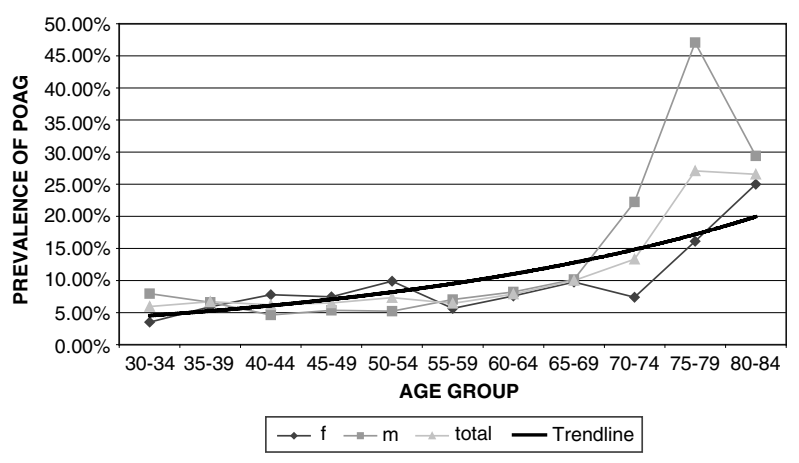

Figure 1 Prevalence age relationship. 
sample population and only 21 were found ineligible. Prevalence rose irregularly after the age of 64 years, giving a high average level of $16.4 \%$ (95\% CI 12.34-20.46) in the 65- to 100-year age group that formed only $17.82 \%$ (318) of the eligible sample population after exclusion of 37 others $(10 \%)$ (commonly due to dense cataracts which made it impossible to assess the optic disc) (Table 3).

The best line fit for POAG prevalence related to age in this study is an exponential curve (Figure 1). A linear trend line equation derived for the prevalence/age relationship gives $r^{2}=0.65$, while an exponential trend line has $r^{2}=0.7565$.

The major self-reported ethnic groups (tribes) were Akwapim 55\%, Ewe 15\%, and Ga and Adangbe 9\% (Figure 2). The Ga Adangbe, the Northern tribes, and others were too heterogeneous and/or their numbers were too small to make any meaningful comparisons. The prevalence of POAG in the Akwapims was 9.44\% compared to $8.79 \%$ in the Ewes $(P>0.7)$ (Table 4). There was no statistically significant variation in ethnic prevalence of POAG in this population.

\section{Discussion}

To our knowledge, this is the first attempt at a population study of POAG in West Africa, although logistics and local factors did not allow a true random selection of participants. Such local factors and difficulty in obtaining adequate funds for research in developing countries such as Ghana posed constraints that resulted in the adoption of selection criteria that may have introduced unquantifiable bias into the sampling. A volunteer sample, as used in this study, has limitations of 'healthy or unhealthy volunteer effects'. A healthy volunteer

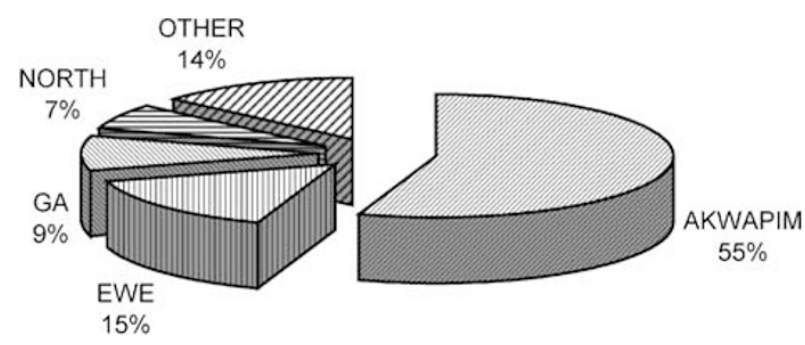

Figure 2 Self-reported tribes.

Table 3 Confidence intervals (95\%) for prevalence of glaucoma

\begin{tabular}{lccc}
\hline $\begin{array}{l}\text { Age group } \\
\text { (years) }\end{array}$ & $\begin{array}{c}\text { Number of } \\
\text { subjects }\end{array}$ & $\begin{array}{c}\text { Prevalence of } \\
\text { POAG }(\%)\end{array}$ & $\begin{array}{c}\text { Confidence } \\
\text { interval }\end{array}$ \\
\hline $30-100$ & 1785 & 8.4 & $7.74-9.06$ \\
$30-64$ & 1467 & 6.6 & $5.46-7.76$ \\
$65-100$ & 318 & 16.4 & $12.34-20.46$ \\
\hline
\end{tabular}

effect would result in poor participation of individuals with severe visual impairment, while an unhealthy volunteer effect on the contrary would lead to a higher response from those with eye problems as there was only one ophthalmologist within the district. It would have been better, in principle, to select the villages at random as there are potential biases in selecting villages by 'accessibility by roads'. However, local knowledge confirms that such bias is fairly low. The inclusion of relatives also introduces a potential bias since glaucoma runs in families and would tend to overestimate the prevalence when relatives with more than one family member affected are included in the study. However, in this study, only $6.9 \%$ of glaucoma cases had a positive family history of glaucoma in first-degree relations. Another potential flaw in this study is that glaucoma cases were diagnosed by one ophthalmologist.

Furthermore, IOP measurement with the Perkin's tonometer is generally examiner dependent. However, the intraobserver variations were negligible. The direct ophthalmoscope was used for the initial examination despite its limitation of monocular nonstereoscopic assessment of the optic disc. Unfortunately, financial limitations prevented the adoption of other more stringent methodologies.

Despite the above limitations, this study shows that the prevalence of POAG is high in the Akwapim-South district population. A lower prevalence of $2.42 \%$ of POAG in Caucasians was reported in Quigley's review of glaucoma prevalence worldwide. ${ }^{9}$ This prevalence seems to be uniform for all European communities (Table 5). Comparatively high prevalence rates of POAG have been documented in black populations in the West Indies, particularly St Lucia: $8.8 \%,{ }^{10}$ Barbados: $7.1 \%,{ }^{5}$ and then in Baltimore, United States: $4.74 \% .{ }^{11}$ The Barbados study also found a prevalence of $0.8 \%$ in white populations, although the population had a relatively smaller white sample size of 133 . The Baltimore study found a prevalence of $1 \%$ in a larger sample size of 2913 white individuals (Table 5). Such high prevalence in a population-based study has not been previously documented in West Africa. Indeed, it has been speculated that although the population of Barbados was derived from West Africa, there may be nutritional or environmental influences in Barbados that were absent in Africa. Furthermore, it has been suggested that genes were thought to have altered the prevalence of glaucoma in the Barbados population from the parent African population. ${ }^{12}$ However, the high prevalence rates of POAG in these black communities are comparable to our results. A recent population-based study on blindness in Gambia, West Africa found a lower prevalence of $1.0 \% .^{13}$ However, the Gambia study was a study on blindness and not prevalence of glaucoma per se. 
POAG accounted for $94 \%$ of all the glaucomas diagnosed in this study. These include $20.9 \%$ of normal tension glaucoma (NTG). Gonioscopy was not routinely performed in most of the previously reported glaucoma studies in Ghana. It was, therefore, not possible to distinguish POAG from other types of chronic glaucoma in those studies. ${ }^{14-16}$ One recent study performed gonioscopy in 198 'glaucoma' patients attending a clinic in Ghana where visual fields were not routinely performed. ${ }^{16}$ These investigators used a modified tangent screen with a laser pointer as the target and found that the most common form of glaucoma was POAG in $44.2 \%$. Primary angle closure glaucoma accounted for $6.6 \%$, and the remaining $30.5 \%$ were classified as glaucoma suspects. ${ }^{16}$ The clinic where the study was reported from has a high turnover of ophthalmologists with various levels of training and qualification, who were contracted for varying periods, and it is possible that interobserver agreement was variable.

It was reported in an earlier study on IOPs in Ghanaians that $8 \%$ of the population had IOPs of $5-10 \mathrm{mmHg} .{ }^{17}$ Increases in IOPs of $11-16 \mathrm{mmHg}$ in such persons will maintain their IOPs in the normal range. However, for the particular individuals, these IOP changes would have been significant increases that may be associated with optic nerve damage. As such, if high IOP alone were used as a major criterion for the diagnosis of glaucoma, they would be classified as normal. Two hospital-based studies in Ghana ${ }^{15,16}$ used high IOP as a criterion for diagnosing glaucoma while reporting features of glaucoma in Ghana. By definition, therefore, they did not include the NTG. Others did not define their investigation criteria for diagnosis of glaucoma. ${ }^{15}$ As such, it was not possible to tell whether they included NTG or not. In the Gambian national study, $50 \%$ of the POAG were of normal tension type. ${ }^{13}$ Different proportions of NTG in various populations appear in the literature (Table 6). Biostatistical analysis showed that among people over 60 years old, up to $3.7 \%$ of those with an IOP of $16-19 \mathrm{mmHg}$ will have glaucomatous visual field defects in 5 years. ${ }^{18}$

In our study, $94 \%$ of the glaucoma cases diagnosed were unaware that they had glaucoma, a much higher proportion than previously reported..$^{5,11,19-22}$ This is probably partly because most of the new cases were found in younger participants compared to other studies. This is in agreement with Weih et $a^{\prime}{ }^{\prime}{ }^{19}$ suggestion that younger patients were at greater risk of having undiagnosed POAG. It is, however, also possible that some of the apparently newly diagnosed cases had been previously diagnosed elsewhere, but were unaware that they had the disease at the time of this study.

This study does not demonstrate any gender difference in the prevalence of POAG. Although there appear to be inconsistencies in the literature on gender variation in the

Table 5 Prevalence of glaucoma in different Races

\begin{tabular}{lllc}
\hline Racial origin & Location & Age & POAG (\%) \\
\hline Africa & Gambia, West Africa & $30+$ & 1.2 \\
& Barbados, West Indies & $40-84$ & 7.1 \\
& St Lucia, Caribbean & $30+$ & 8.8 \\
& Baltimore, USA & $40+$ & 4.74 \\
& Akwapim-South district, & $30+$ & 7.7 \\
European & Ghana, West Africa & $40+$ & 8.5 \\
& Rotterdam, Netherlands & $55+$ & 1.10 \\
& Barbados, West Indies & $40-84$ & 0.8 \\
Australia & Baltimore, USA & $40+$ & 1.29 \\
& Sydney, Australia & $49+$ & 3.0 \\
Mixed race & Victoria, Australia & $40+$ & 1.8 \\
& Barbados, West Indies & $40-84$ & 3.3 \\
\hline
\end{tabular}

Table 6 Glaucoma prevalence/NTG

\begin{tabular}{lrcc}
\hline Study and location & $\begin{array}{c}\text { Age range } \\
\text { of subjects } \\
\text { (years) }\end{array}$ & $\begin{array}{c}\text { Prevalence } \\
\text { of glaucoma } \\
(\%)\end{array}$ & $\begin{array}{c}\text { Normal } \\
\text { IOP } \\
(\%)\end{array}$ \\
\hline Akwapim-South, Ghana & $30+$ & 7.7 & 21 \\
Gambia & $30+$ & 1.0 & 50 \\
Rotterdam, Netherlands & $55+$ & 1.10 & 38.9 \\
Hollows et al, Ferndale, Wales & $55-70$ & 0.47 & 35 \\
Liebowitz et al, Framingam, & $52-85$ & 1.43 & 53 \\
MA, USA & & & \\
Stromberg, Skovde, Sweden & $>40$ & 0.41 & 13 \\
Stromberg, Dalby, Sweden & $>40$ & 0.86 & 62 \\
Bankes et al, Bedford, England & $>40$ & 0.76 & 7 \\
Armaly, Des Moines, Iowa & $20-89$ & 4.08 & 68 \\
\hline
\end{tabular}

Table 4 Prevalence of glaucoma by ethnicity

\begin{tabular}{lllll}
\hline Tribes & \multicolumn{4}{c}{ Age groups (years) } \\
\cline { 2 - 5 } & \multicolumn{1}{c}{$30-39$} & \multicolumn{1}{c}{$40-64$} & $>64$ & Total \\
\hline Akwapim & $6.41 \%(15 / 234)$ & $7.36 \%(39 / 530)$ & $17.65 \%(39 / 221)$ & $9.44 \%(93 / 985)$ \\
Pooled all non-Akwapim & $5.78 \% 14 / 242$ & $6.29 \% 29 / 461$ & $13.40 \% 13 / 97$ & $7.00 \% 56 / 800$ \\
Ewe & $6.93 \%(7 / 101)$ & $7.915 \%(11 / 139)$ & $18.18 \%(6 / 33)$ & $8.79 \%(24 / 273)$ \\
\hline
\end{tabular}


prevalence of POAG, the weight of evidence indicates that there are no true gender variations. ${ }^{9,11,12,22}$ However, in the Rotterdam population study, the prevalence was higher in males, with men having three times higher risk of having POAG than women. ${ }^{22}$ In the Barbados Eye study, the male-female age-adjusted ratio was $1.4 .^{5}$ Different hospital studies from Ghana found a male preponderance of $71^{14}$ and $65 \%,{ }^{23}$ and a female preponderance of $51 \% .{ }^{16}$ This probably demonstrates bias usually associated with hospital attendances and records and local factors that influence access to eye care.

By the age of 30 years, prevalence was already high (6.0\%). This confirms clinical observations by many clinicians in West Africa and elsewhere that the onset of POAG is earlier in black individuals than Caucasians.

One hospital study in Northern Ghana found that 21.48\% of patients with chronic glaucoma were in the 10- to 39year age group. ${ }^{14}$ In view of the above, there is a need for further research to determine the appropriate age at which to start screening for glaucoma, especially when there is a positive family history. Determination of the age of onset of POAG has important implications on developing eye care services in West Africa.

As expected, there was an increased prevalence of glaucoma with age. The apparent drop in prevalence between 80 and 90 years may be related to the small number of subjects as fewer people exist in this age group. Indeed, only $10 \%$ of the national population is aged above 64 years (Ghana Statistical Service, Min of Economic Affairs, Accra). The large increase in prevalence with age, reaching $16.4 \%$ in the patients over 65 years, seems to parallel that of the Barbados study. ${ }^{5}$ The present study in a Ghanaian population, in contrast to Quigley's analysis of glaucoma in black populations, therefore, found an exponential trend line for prevalence of glaucoma with age. However, there is a significant shift of the trend line curve upwards and to the left of Quigley's derivation for Caucasian populations.

No ethnic variation was observed in the prevalence of glaucoma between the two most highly represented tribes (ie the Akwapims and the Ewes, $P$-value $>0.7$ ), or between the Akwapims and all other tribes pooled $(P$-value $>0.06)$ in our study. However, it is worth noting that there were relatively fewer participants from the Ewe tribe compared to the Akwapims. This is not unexpected because of the known origins of these different tribes. The dominance of one ethnic group may have confounded the results. It is also probable that there have been intermarriages between the different tribes within the region. However, the level of intertribal marriages was not ascertained during this study. These results may, however, be a true representation of an absence of tribal differences in the prevalence of glaucoma in Ghana. The ethnic diversity would be similar to that in other nonmetropolitan districts in Ghana, where there is a predominance of the indigenous tribe (Akwapim in this study district) and then a mixture of other tribes. In the five metropolitan districts of Ghana, the tribes are more evenly distributed. A multicentre population study involving populations in the different regions of Ghana (representing the different tribal dominances) will provide more complete data on the national prevalence and any tribal differences that may exist in the prevalence of POAG in Ghana.

Despite its limitations, this study confirms speculations among clinicians that onset of glaucoma is earlier and the prevalence is higher in people of African origin compared to Caucasians. Hopefully, it will stimulate further research in glaucoma in the West Africa subregion.

\section{Acknowledgements}

Professor S Odoom, Dr Aaron Offei, Rev A Kwansa, and staff of Kom Clinic contributed to the development of the protocol. GK Okyere coordinated the field assistants. Kwabena Ntim Amponsah and James Ntim Amponsah helped with data processing. James Ntim Amponsah, spouse of the principal investigator, also provided the major financial support for this study. Other contributors were Alcon/Paracelsus Pharmacy, Pharmacia and UpJohn and Clark foundation. Dr P Egbert loaned a tonopen from Stanford University Medical School of California.

\section{References}

1 Murdoch I. Epidemiology and primary open angle glaucoma. Community Eye Health 1996; 9(18): 19-22.

2 Adu-Darko M. Common causes of blindness in Southern Ghana as seen in Komfo Anokye teaching hospital in Kumasi. Ghana Med J 1991; 25: 280-284.

3 Hagan M. 2000 Eye Care Report. Ministry of Health, Ghana.

4 Quarcoopome CO. Editorial: eye diseases in Ghana. Ghana Med J 1991; 23: 266.

5 Leske CM, Connell AMS, Schachat AP, Hyman L. The Barbados Eye Study. Archiv Ophthalmol 1994; 112: 821-829.

6 Ghana Demographic and Health Survey Report 1998. Summary Report, p 16. Ministry of Health, Accra, Ghana.

7 Ntim-Amponsah CT. Visual loss in chronic glaucoma patients. Trop Doctor 2002; 32: 1-3.

8 Tenkorang K. 2000 Annual report of Akwapim South district. Ministry of Health, Accra, Ghana, 2002.

9 Quigley HA. Number of people with glaucoma worldwide. Br J Ophthalmol 1996; 80 5): 389-393.

10 Mason RP, Kosok O, Wilson MR, Martone JP, Cowan CL, Gear JC et al. National prevalence and risk factors of Glaucoma in St Lucia, West Indies. Ophthalmology 1989; 96: 1363-1368.

11 Tielsch JM, Sommer A, Katz J, Royal RM, Quigley HA, Javitt $\mathrm{J}$. Racial variations in the prevalence of primary open angle 
glaucoma: The Baltimore Eye Survey. JAMA 1991; 266: 369-374.

12 Johnson GJ. In: Johnson GJ, Minassian DC, Weale R (eds). The Epidemiology of Eye Disease, Chapman \& Hall Medical, Lippincott-Raven Publishers: London, Chapter 8, 1998, p. 76.

13 Faal H, Chuka-Okosa C. Year 2000 National Survey on Blindness in Gambia. Ministry of Health, Banjul, Gambia 2002.

14 Verrey JD, Foster A, Wormald R, Akuamoa C. Chronic glaucoma in Northern Ghana. A retrospective study of 397 patients. Eye 1990; 4: 115-120.

15 Hagan M, Akafo S, Acheampong F, Ackuaku E, Odame F, Oduro T et al. Primary open angle glaucoma at Korle-Bu Teaching Hospital. Ghana Med J 1991; 23: 280-294.

16 Herndon LW, Ababio-Danso B, Boateng JO, Challa P, Broomer B, Ridenhour P et al. Types of glaucoma in a Ghanaian clinic. Invest Ophthalmol Vis Sci 2001; 42: $\mathrm{s} 115$.

17 Ntim-Amponsah CT. Mean intraocular pressure - a study in Ghanaians. East Afr Med J 1996; 73(8): 22-24.
18 Armaly MF, Krueger DE, Maunder L, Becker B, Hetherington J, Kolker AE et al. Biostatistical analysis of the Collaborative Glaucoma Study. I. Summary report of the risk factors for glaucomatous visual-field defects. Arch Ophthalmol 1980; 98: 2163-2171.

19 Weih LM, Nanjan M, McCarty CA, Taylor HR. Prevalence and predictors of open-angle glaucoma. Ophthalmology 2001; 108: 1966-1972.

20 Coffey M, Reidy A, Wormald R, Wu XX, Wright L, Courtney $\mathrm{P}$ et al. Prevalence of glaucoma in the West of Ireland. Br J Ophthalmol 1993; 77: 17-21.

21 Mitchell P, Smith W, Attebo K, Healey PR. Prevalence of open-angle glaucoma in Australia. The Blue Mountains Eye Study. Ophthalmology 1996; 103: 1661-1669.

22 Dielemans I, Vingerling JR, Wolfs RC, Hofman A, Grobbee DE, Jong PT. The prevalence of primary open-angle glaucoma in a population-based study in the Netherlands. The Rotterdam Study. Ophthalmology 1994; 10: 1851-1855.

23 Wormald R, Foster A. Clinical and pathological features of chronic glaucoma in North-East Ghana. Eye 1990; 4: 107-114. 